\title{
LAS FALSIFICACIONES GRANADINAS DEL SIGLO XVIII. NACIONALISMO Y ARQUEOLOGÍA *
}

\author{
GLORIA MORA \\ JOAQUÍN ÁlVAREZ BARRIENTOS \\ CSIC
}

\begin{abstract}
La verdad es el alma de la Historia; todos desean encontrarla y son pocos los que no viven satisfechos de su hallazgo.

Joaquín Traggia, Aparato a la Historia eclesiástica de Aragón, dedicatoria.
\end{abstract}

Las falsificaciones perpetradas en Granada a mediados del siglo XVIII, famosas en su tiempo sobre todo por la publicidad del juicio que las condenó, han sido estudiadas por diversos autores y desde distintos puntos de vista, especialmente el biográfico-político y el arqueológico ${ }^{1}$. Hace años escribimos un largo artículo ofreciendo un panorama general que relacionaba estas falsificaciones con los falsos cronicones, con el disputado Voto de Santiago y aportando documentación inédita del Archivo Histórico Nacional, de la Real Academia de la Historia, del Archivo de la Catedral de Toledo, de la Biblioteca Nacional y de la Fundación Lázaro Galdiano, entre otras instituciones ${ }^{2}$. De manera especial poníamos en relación estos sucesos con hechos similares del pasado, las falsificaciones de fines del siglo XVI conocidas como los Plomos del Sacromonte, y del presen-

* Este trabajo se ha realizado en el marco de un proyecto financiado por la Comunidad de Madrid.

1 Véase, respectivamente, Sotomayor, M., Cultura y picaresca en la Granada de la Ilustración. D. Juan de Flores y Oddouz, Granada, 1988; Roldán Hervás, J.M., «Arqueología y fraude en la Granada del siglo XVIII: Juan de Flores y las excavaciones del Albayzin», Zephyrus, 37-38 (1984-85), 377-396; Sotomayor, M., «Excavaciones arqueológicas en la Alcazaba de Granada (1754-1763)», en Miscelánea Augusto Segovia, Granada, 1986, 243-283.

2 Álvarez Barrientos, J. y Mora Rodríguez, G., «El final de una tradición. Las falsificaciones granadinas del siglo XVIII», Revista de Dialectología y Tradiciones Populares, XL (1985), 163-189.

Al-Qanțara XXIV, 2 (2003) 533-546 
te, el interés de la Corona por las antigüedades de España con motivo de la redacción de una nueva Historia nacional, lo cual dio lugar a importantes trabajos científicos, como los del marqués de Valdeflores, el padre Flórez o Francisco Pérez Bayer, pero también a manipulaciones de la Historia, de las que son buen reflejo las falsificaciones granadinas ${ }^{3}$.

Estas breves páginas sólo quieren destacar las motivaciones y los objetivos de los falsificadores, en el contexto de la nueva situación política y cultural de la década de 1750 .

\section{Primero los hechos}

Desde época indeterminada aparecían objetos antiguos en la Alcazaba de Granada, situada en las faldas del Albaicín ${ }^{4}$. A partir de 1750 Juan de Flores y Oddouz, racionero de la catedral, adquiere muchas de las antigüedades halladas en esta zona, como consta en los certificados de compra fechados entre el 18 de diciembre de 1750 y el 25 de agosto de 1755, firmados por el propio Flores y los escribanos del rey Francisco de Vilches Zamora y Diego de la Breña ${ }^{5}$.

El 2 de noviembre de 1752 se publicaba una Real Orden de Fernando VI firmada por el marqués de la Ensenada, su ministro de Estado, dando Instrucciones y Órdenes para el viaje del académico de la Real de la Historia Luis José Velázquez de Velasco, marqués de Valdeflores, por Castilla, Extremadura, León y Andalucía. La Orden tercera hacía referencia al objetivo de este viaje: «examinar, copiar y recoger de los archivos, bibliotecas, gabinetes y demás parajes públicos o privados todos los antiguos monumentos de la nación española, que pudieren ser de algún uso para su Historia» ${ }^{6}$. Aprovechando la ocasión, Flores pidió licencia para excavar en lo que se consideraba la parte más antigua de Granada, la Alcazaba, en las faldas del Albaicín.

3 Mora, G., Historias de Mármol. La arqueología clásica española en el siglo XVIII, Madrid, 1998, 31-51 y 87-89.

${ }^{4}$ Roldán, J.M., Granada romana, Granada, 1983.

5 Flores, J. de, Escrituras, papeles y copias de objetos arqueológicos encontrados en la comarca de Granada, coleccionados y estudiados por D. -, Biblioteca de la Fundación Lázaro Galdiano, ms. 244 (sign. 35/4).

${ }^{6}$ Velázquez de Velasco, L.J., Noticia del Viaje de España hecho de orden del Rey, Madrid, 1765, 13. 
Para tal fin compró unas casas en la parroquia de San Nicolás de Bari y comenzó las excavaciones el 24 de enero de 1754. Allí encontró las ruinas de un gran edificio, que supuso era un templo romano, además de estatuas, inscripciones, capiteles y lucernas. La Real Hacienda mandó suspender las obras, aduciendo ser competencia propia, pero Flores, gracias al apoyo de Ensenada (justo antes de ser defenestrado), consigue el permiso de Fernando VI para proseguir sus trabajos bajo la supervisión de una Junta presidida por el mismo Flores y formada, entre otros, por dos personajes que tuvieron un papel importante en los sucesos siguientes: Francisco Luis de Viana, canónigo de la catedral de Granada, y Cristóbal de Medina Conde, canónigo de la de Málaga 7 . A partir de enero de 1755 salieron a la luz «mármoles con caracteres extraños, dedicaciones a diferentes emperadores, aras, láminas de obispos de Iliberia y el primer libro que decían del Concilio Iliberitano» ${ }^{8}$.

Los hallazgos despertaron en seguida la curiosidad popular, repitiéndose escenas semejantes a las producidas cuando el descubrimiento de los Plomos del Sacromonte a fines del siglo XVI: procesiones, rogativas, misas, etc. También desde muy pronto se despertaron los recelos de algunos eruditos de gran prestigio en España y fuera de ella, como Gregorio Mayans, el padre Enrique Flórez, el padre Martín Sarmiento y Francisco Pérez Bayer. Uno de los primeros en manifestar en público sus dudas - puesto que Mayans, por ejemplo, prefirió el ámbito privado de las cartas ${ }^{9}$ - fue Tomás Andrés de Gusseme, académico de la Real de Buenas Letras de Sevilla, quien ya en 1760 escribió unas Desconfianzas críticas sobre algunos monumentos de antigüedad que se suponen descubiertos en Granada en las excavaciones de la Alcazaba desde el año de 1753, impugnando los hallazgos con argumentos filológicos, epigráficos y numismáticos, que fueron refutadas (chapuceramente) por Medina Conde ${ }^{10}$. Sin embargo, el padre Flórez, que por entonces escribía su historia de España y con-

\footnotetext{
7 A esta Junta se añade unos meses más tarde Ensenada, retirado en Granada de la vida política.

8 Razón del Juicio seguido en la ciudad de Granada [...] contra varios falsarios de escrituras públicas, monumentos sagradas, y profanos, caracteres, tradiciones, reliquias y libros de supuesta antigüedad, Madrid, 1781, 110.

9 Mestre, A., Ilustración y reforma de la Iglesia, Valencia, 1968, 197-206.

10 El ms. 9/4027 de la Real Academia de la Historia contiene la documentada crítica de Gusseme y la respuesta de Medina Conde.
} 
taba con el aval de la Academia de la Historia, eludió la espinosa cuestión arqueológica en el t. XII de su España Sagrada (1754), dedicado precisamente a la Iglesia de Iliberri, y se limitó a analizar sólo las fuentes escritas; por el contrario, la participación de Pérez Bayer y Sarmiento contra las falsificaciones fue más activa, emitiendo informes y entrevistándose con los implicados ${ }^{11}$.

En 1763, al cabo de nueve años de trabajos y descubrimientos auténticos y falsos, Flores tuvo que suspender las excavaciones por falta de fondos, aunque en los años siguientes siguió enviando informes a Madrid con el deseo de obtener el favor del hebraísta Francisco Pérez Bayer, muy influyente entonces en la Corte y preceptor de los hijos de Carlos III, y del padre Sarmiento. Pero Flores fue delatado por uno de sus cómplices y detenido la noche del 12 de junio de 1774. Unos días antes, como consecuencia de los informes desfavorables de especialistas españoles ya mencionados y otros extranjeros (Tassin, Barthélemy, La Condamine), habían comenzado por Real Decreto de Carlos III las averiguaciones sobre los extraordinarios descubrimientos que venían sucediéndose en la Alcazaba de Granada desde 1754.

Desde el primer momento los hallazgos se vincularon a los de dos siglos antes, los llamados Plomos del Sacromonte, gracias a la aparición de objetos de carácter religioso, planchas de plomo con inscripciones en lengua desconocida y otras en las que se aludía al concilio iliberritano. Algunos, no obstante, son auténticos: al menos nueve inscripciones ${ }^{12}$, monedas romanas y visigodas, fragmentos arquitectónicos (cornisas, columnas, capiteles y basas), restos constructivos de un gran edificio con pórticos y escalinatas y cipos y lápidas a ambos lados, y un pavimento enlosado, todo lo cual llevó a pensar que se trataba (como así es) del Foro romano de la ciudad, el Municipio Florentino Iliberritano mencionado en algunas inscripciones ${ }^{13}$. El mismo Flores insistía en la relación con los Plomos en una carta al marqués de Grimaldi, ministro de Estado, fechada en diciembre de 1764: «aunque dichos descubrimientos supongan en realidad fábrica y monumentos antiguos de la gentilidad todo lo eclesiástico y sagrado es

11 Cf. Álvarez Barrientos y Mora Rodríguez, «El final de una tradición», 176-180.

12 Recogidas por E. Hübner en CIL II, n. ${ }^{\circ} 2073,2076,2077,2079,2080,2082,2085$, 2086, 2089.

13 Gómez Moreno, M., Misceláneas, Madrid, 1949, 368-369; Vega, Fr. Á.C., España Sagrada, t. LIII y LIV, De la Santa Iglesia Apostólica de Iliberri (Granada), Tratado Primero, Madrid, 1961. 
fraguado en la misma oficina que lo empezado a descubrir en el año de $1595{ }^{14}$.

A raíz del juicio y la condena de los falsarios se ordenó en 1777 la destrucción de los objetos falsos y el terraplenado de las ruinas descubiertas, y además se prohibieron ulteriores investigaciones en aquel lugar. Sólo quedan, como constancia de lo descubierto, los planos y dibujos realizados por Juan de Villanueva o Pedro Arnal en 1766 y por el pintor Diego Sánchez Saravia en 1768, conservados en la Real Academia de la Historia ${ }^{15}$. Todavía en 1782, durante su viaje por Andalucía, Francisco Pérez Bayer pudo ver en los sótanos de la Real Chancillería de Granada materiales y papeles procedentes de las excavaciones de Flores, tanto auténticos como falsos ${ }^{16}$.

\section{Las motivaciones}

Hasta aquí los hechos, que responden a motivaciones diversas pero que básicamente pueden reducirse a dos y que se vieron favorecidas por el nuevo ambiente historiográfico que propició la monarquía borbónica.

Como decimos, el origen de las falsificaciones se ramifica en un conjunto de factores relacionados entre sí, pero todos ellos con el leit-motiv del uso de la arqueología con fines políticos. La idea humanista de que, en la redacción del discurso histórico, la evidencia material era tanto o más fiable que los textos de la Antigüedad, resumida por Rodrigo Caro en la expresión "otras historias hay de mármol», acaba en el siglo XVIII pervirtiéndose en la afirmación de Cristóbal de Medina Conde: «por los monumentos, no hay duda, se corrigen las historias, y se han corregido siempre» ${ }^{17}$, declaración de intenciones que pone de relieve que para muchos el conocimiento de la Historia

\footnotetext{
${ }^{14}$ Citada por Vega, España Sagrada, 45.

15 Para una valoración de los hallazgos auténticos, cf. Sotomayor, «Excavaciones arqueológicas», 274-278.

16 Pérez Bayer, F., Diario del viaje desde Valencia a Andalucia hecho por Don en este año de 1782, en Mestre Sanchís, A., Pérez García, P., Catalá Sanz, J. A. (eds.), Francisco Pérez Bayer. Viajes literarios, Valencia, 1998,184-185. Algunas inscripciones pasaron de la Real Chancillería al Museo Arqueológico Provincial de Granada.

17 R. Caro, Memorial de la villa de Utrera, 1604, cap. II, en Obras de..., I, Sevilla, 1883; C. Medina Conde, Cartas II del sacristán de Pinos de la Puente al autor del Cajón nuevo de sastre, Barcelona, 1762, 114.
} 
no era un fin en sí mismo, sino un medio para otras cosas: para justificar privilegios, viejas tradiciones y creencias o para legitimar monarquías.

\section{La antigüedad como argumento}

El interés de la monarquía hacia las antigüedades del país por razones políticas no es nuevo, ya que tenemos ejemplos en tiempos de los Reyes Católicos y de Felipe II ${ }^{18}$, pero sí es especialmente característico de los reyes borbones. Los motivos son varios. En primer lugar, se recurre a la antigüedad como modelo en política y en arte para autorizar la presencia de una nueva dinastía, vinculándola visualmente al pasado ${ }^{19}$. Por otro lado, la perspectiva de la firma del nuevo Concordato con la Santa Sede impulsa la búsqueda de documentos, textuales y materiales, antiguos, medievales y modernos, que confirmaran las pretensiones de la Corona en su lucha contra el Papado por la cuestión de la posesión de los beneficios eclesiásticos.

A ello se suma la iniciativa de redactar una nueva Historia nacional «libre de falsedades y leyendas», encargo que recibió la Real Academia de la Historia fundada por Felipe V en 1738. Éste fue el pretexto para recorrer archivos y bibliotecas y recopilar inscripciones y otras antigüedades en los últimos años cuarenta y primeros cincuenta del siglo XVIII. Es la gran empresa de los llamados viajes literarios, promovida por el marqués de la Ensenada, ministro de la Secretaría de Estado, y financiada por Fernando VI, entre los cuales destaca el realizado por Luis José Velázquez de Velasco, más tarde marqués de Valdeflores, por Castilla, Extremadura, León y Andalucía entre 1752 y $1755^{20}$.

La Real Orden de 2 de noviembre de 1752, que determinó el viaje de Valdeflores, tuvo además el efecto inmediato de propiciar activi-

${ }^{18}$ Mora, G., «The image of Rome in Spain: scholars, artists and architects in Italy in the 16th-18th c.», en Hingley, R. (ed.), Images of Rome. Perceptions of ancient Rome in Europe and the United States in the modern age, Portsmouth, Rhode Island, 2001, 24-27.

19 Mora, Historias de Mármol, 48-51. Un caso paradigmático de esta lectura de la antigüedad se encuentra en el programa iconográfico para adornar el Palacio Real de Madrid: Martín Sarmiento, Sistema de adornos del Palacio Real de Madrid, Álvarez Barrientos, J. y Herrero Carretero, C. (eds.), Madrid, 2002.

${ }^{20}$ Mora, Historias de Mármol, 41-44. Tras la caída de Ensenada se le suspendió la pensión, pero Valdeflores siguió viajando a sus expensas hasta 1765. 
dades arqueológicas locales, ya que muchas poblaciones manifestaron su deseo de poseer los monumentos más antiguos de la nación. Así, el propio Medina Conde confesó que «esta sabia providencia de la Real Academia motivó en realidad de verdad, haciendo justicia, toda la invención de la Alcazaba» ${ }^{21}$. La observación de Medina es ambigua porque en la época la palabra «invención» significaba tanto hallazgo como creación, es decir, como falsificación. De modo que con ese término el canónigo de Málaga, aludiendo a los descubrimientos reales, encubría los falsos, pero, si recordamos su declaración de que «los monumentos corrigen las historias», esa frase pierde mucha de su ambigüedad.

\section{Nacionalismo y política}

Como hemos dicho, el proyecto de la Academia de la Historia era escribir una Historia de España nueva y moderna, desbrozada de los errores y falsedades que tradicionalmente la acompañaban. Este propósito intelectual tenía una raíz científica, basada en la asunción de la crítica como método científico, y tenía, a su vez, una intención política clara, que está incluso detrás de la constitución de la misma Academia: que la monarquía se dotara de unos textos y un cuerpo de científicos que produjeran obras que justificaran los derechos de la nueva dinastía y su política frente a la Santa Sede, cuyo poder e influjo se quería minimizar.

Pero no sólo frente a la Iglesia. Durante el siglo XVIII España sufre una serie de acosos, tanto bélicos (que le llevan a perder importantes zonas de su imperio), como propagandísticos (leyenda negra, Inquisición, conquista de América, banalidad de la cultura nacional), que llevaron a los gobernantes a trazar un programa para contrarrestar esos ataques. Un ejemplo temprano es la publicación en 1756, en Roma, de un tratado de Francisco Pérez Bayer en defensa del origen hispano de los santos Lorenzo y Dámaso, titulado Damasus et Laurentius hispani asserti et vindicati, que, como ha señalado Antonio Mestre, debe vincularse con la política de defensa y reivindicación de la cultura española frente a las críticas extranjeras, promovida por el grupo de manteístas y antijesuitas que había derrotado al marqués de la Ense-

${ }^{21}$ En la Carta I del Sacristán de Pinos, 63. 
nada (Pedro Rodríguez Campomanes, Manuel de Roda, Ricardo Wall). El mismo Pérez Bayer, en carta a Gregorio Mayans fechada en Roma a 19 de enero de 1757, definía su tratado como un «conato a favor de la patria» 22 .

Así, como parte de ese programa de reformas y defensa de las acusaciones foráneas, de reconstrucción del pasado nacional y de su interpretación más precisa, se revisará la historia de la conquista, se creará el Archivo de Indias y se pondrá en marcha toda otra serie de acciones entre las que destacan, en estas fechas de mediados de siglo, la escritura de historias de la cultura española, que darán una imagen más precisa, veraz y científica de lo que fue el pasado nacional. Casi todas se comenzaron en los años del reinado de Fernando VI, y todas responden a los mismos planteamientos. Por un lado, al nuevo sentido historicista del siglo y, por otro, a la consideración, creciente en Europa, de que la cultura es un arma útil para influir sobre los países.

De este modo, el padre Martín Sarmiento, figura de gran predicamento en la Corte durante los reinados de los dos primeros Borbones, escribió unas Memorias para la historia de la poesía y de los poetas castellanos (1745) que sólo se publicaron en 1775; Luis José Velázquez publicaba en 1754 el que pasa por ser el libro fundacional de la historia literaria española: los Orígenes de la poesía castellana, que, además de otros valores, posee el de acuñar la expresión «Siglo de Oro» para esa época de la historia de la literatura que aún se conoce de ese modo. Años antes, otros personajes cercanos al poder, como Blas Nasarre y Agustín de Montiano, habían hecho sus historias de la comedia y la tragedia españolas, y a estos trabajos siguieron otros que asentaban los cánones mediante antologías de poesía, teatro y prosa - véanse las de García de la Huerta, Tomás Antonio Sánchez, Francisco Cerdá y Rico y Antonio de Capmany-, y nuevas historias literarias y de la cultura, éstas ya de mayor empeño, como la Historia literaria de España, iniciada en 1766 en Granada por los hermanos Rodríguez Mohedano, la Historia de España y de la cultura españo-

22 Mestre, A., «Estudio Preliminar», en G. Mayans y Siscar, Epistolario VI. Mayans y Pérez Bayer, Valencia, 1977, 190. La afirmación de la «españolidad» de San Lorenzo era un tema tradicional en la historiografia aragonesa, al menos desde la defensa hecha ya por Juan Francisco Andrés de Uztarroz a comienzos del siglo XVII (Andrés de Uztarroz y Dormer, Progresos de la historia de Aragón, 1. ${ }^{a}$ parte, Zaragoza, 1878), si bien algunos ilustrados, como Mayans, la rechazan de plano (carta a Pérez Bayer, en Mayans y Siscar, Epistolario VI, 182). 
la, del ex jesuita Masdeu y, sobre todo, Origen, progresos y estado actual de toda la literatura, del abate Juan Andrés, donde se traza el panorama de la producción cultural universal y se valoran las aportaciones al acervo común de cada país en las diferentes etapas de la civilización. Juan Andrés destaca de manera original el importante papel que la cultura árabe, junto con la griega y la latina, comúnmente aceptadas, jugó en la configuración de Europa.

Estas historias, y las apologías que principalmente se desarrollaron desde 1782 , respondían a la ya señalada motivación de carácter político y nacionalista. Hay que recordar que no sólo se escribieron historias literarias, también se realizaron trabajos similares en otras áreas de la cultura ${ }^{23}$.

Pero para realizar una historia veraz y cierta, además de aplicar criterios científicos (los de las ciencias naturales) y críticos, había que tener sobre qué aplicar esos métodos, y ésta es la razón de los viajes de reconocimiento de archivos, en especial eclesiásticos, por toda la geografía nacional. Era necesario saber de qué se disponía, reconocer y recoger los documentos, los diferentes tipos de letras, establecer correctas cronologías, etc., y, en este proyecto, los testimonios monumentales eran tan importantes como los textuales. De ahí que se valorara el ámbito anticuario, es decir, el reconocimiento, estudio y, en ocasiones, traslado, de los vestigios del «glorioso pasado nacional»: monumentos y ruinas, inscripciones, colecciones de monedas y otros objetos, que eran depositados en la Academia de la Historia, en el Gabinete de Medallas de la Real Biblioteca y en el Gabinete de Historia Natural.

En el marco señalado es en el que se comenzaron a producir los hallazgos de las falsificaciones, que se iniciaron en 1755. Sin lugar a dudas los falsificadores aprovecharon este interés general para intentar conseguir beneficios específicos de carácter económico, pues, de haberse aceptado la supuesta mayor antigüedad de Granada como sede episcopal, frente a Santiago de Compostela, Toledo, Tarragona y Sevilla, de mayor tradición, los impuestos recibidos finalmente por la sede gallega habrían ido a parar a la ciudad andaluza. Por otro lado, junto a esta intención, se encuentra lo que Feijoo llamó «amor de la patria», que él entendía como una de las limitaciones para conseguir

${ }^{23}$ Cf. los trabajos reunidos en Aguilar Piñal, F. (ed.), Historia literaria de España en el siglo XVIII, Madrid, 1996. 
un sentimiento nacional real y amplio, pues a casi todos les faltaba esa dimensión que identificara la patria con la nación, mientras que exageraban el amor a la «patria chica» ${ }^{24}$. Años después, el mismo Sempere criticaba la proliferación de historias locales, escritas sin la perspectiva más amplia de los hechos nacionales y por personas sin la capacidad pertinente, lo que redundaba en la escasa utilidad y en la falta de crítica ${ }^{25}$.

En un primer momento puede parecer que Flores y los demás falsificadores solamente se dejaron llevar por ese sentimiento mal entendido de amor a su localidad, al que sumaron intenciones más prácticas. Sin embargo, conviene retener que la idea de patria y de nación, en el siglo XVIII, no era tan amplia como puede serlo hoy; la idea de patria de un campesino no iría más allá del horizonte que contemplara y de los viajes que pudiera hacer a la ciudad más cercana, y lo mismo se puede decir de quienes vivían en otros centros urbanos. De modo que la actividad falsificadora de estos hombres, al margen los aspectos delictivos, se encuadraba en este concepto reducido de «amor a la patria chica» ${ }^{26}$.

\section{Intereses locales}

Este «amor a la patria» se manifiesta en dos aspectos. Por un lado, un objetivo más inmediato, como era el interés del canónigo Viana, abad de la iglesia colegial del Sacromonte y uno de los instigadores de las falsificaciones, que había sido encargado oficialmente - por Real Orden de Fernando VI de 16 de septiembre de 1756- de escribir una «historia de los antiguos descubrimientos» del Sacromonte, es decir, los de fines del siglo XVI, por lo cual estaba muy interesado en que apareciesen documentos relativos a aquellos sucesos ${ }^{27}$. Precisamente en esa época, mediados de siglo, existía un enfrentamiento en-

${ }^{24}$ Feijoo, B. J., «Amor de la patria y pasión nacional», Teatro crítico universal, III, Madrid, 1729 , disc. 10.

${ }^{25}$ Sempere y Guarinos, J., Ensayo de una biblioteca española de los mejores escritores del reinado de Carlos III, VI, Madrid, 1789, 137, 153-154.

${ }^{26}$ Para conocer cómo se forjaron los conceptos de nación y patria, véase Álvarez Junco, J., Mater dolorosa. La idea de España en el siglo XIX, Madrid, 2001.

${ }^{27}$ Viana, L. F. de, y Laboraría, J. J. de, Historia auténtica del hecho de los descubrimientos de Torre Turpiana y Monte Sacro de Granada..., ms. C55 (y copia en C52) de Hagerty, M., "Catálogo de manuscritos», en La Abadia del Sacromonte. Exposición artístico-documental. Estudio sobre su significación y origen, Granada, 1974. 
tre los colegios granadinos (el Colegio del sacro Ilipulitano monte de Granada contra el de los santos apóstoles San Bartolomé y Santiago) por la posesión de las reliquias del Sacromonte y otros privilegios ${ }^{28}$.

Complementario de este interés concreto era la reivindicación del origen cristiano de Granada por parte de los falsarios. Para llevar a cabo sus intenciones necesitaban manipular la Historia, es decir, inventar un pasado que demostrara que Granada, última ciudad en ser rescatada del dominio musulmán, tenía sin embargo una tradición en esa fe que se remontaba a los primeros tiempos del cristianismo, lo cual se evidenciaría encontrando testimonios de su primer concilio celebrado en España, que habría sido el de Iliberri, el año 304. Ahora bien, la identificación de esta ciudad, mencionada en las fuentes grecolatinas ${ }^{29}$, en las monedas ${ }^{30}$ e inscripciones ${ }^{31}$, era muy discutida: había partidarios de situarla en la propia Granada (F. Bermúdez de Pedraza, el padre Flórez), otros la colocaban en los alrededores de Sierra Elvira (Diego Hurtado de Mendoza, Luis del Mármol, Ambrosio de Morales) ${ }^{32}$. A los falsarios les convenía, evidentemente, encontrar pruebas de que la antigua Iliberri era la actual Granada.

De este modo, si, como señaló Jovellanos, la Historia había de servir a los intereses de la Corona, lo que implicaba cierta permisividad con aquellas «correcciones» que fueran en esa dirección, los falsarios granadinos del XVIII, varios de ellos historiadores o aficionados, no dudaron en introducir los elementos necesarios para «corregir» la Historia y que ésta dijera aquello que debía decir y que, en este caso, precisamente, acabó coincidiendo con la realidad histórica, puesto que Iliberri era Granada.

Así pues, a la vista de los objetivos de los implicados y de sus motivaciones, se puede pensar que no habían comprendido aún el verdadero sentido de los nuevos métodos científicos, ni la idea de historicidad, pues falseaban los hechos y los «monumentos» en su propio beneficio. Sin embargo, quizá sea al revés. Los falsificadores, conscientes del hecho diacrónico, procuraron ofrecer testimonios de tiempos antiguos, y en este aspecto eran absolutamente modernos, pues la

28 Álvarez Barrientos y Mora Rodríguez, «El final de una tradición», 174.

29 Ptolomeo, Geog., 2.4.9, Plinio, NH, 3.9.

30 García-Bellido, M. P. y Blázquez, C., Diccionario de cecas y pueblos hispánicos, II, Madrid, 2001, s.v. Iliberri.

${ }_{31}$ Una recopilación reciente en TIR, J-30, Madrid, 2002, s.v. Iliberri.

32 Sobre este debate, cf. Vega, España Sagrada, 36. 
nueva ciencia desde Newton y antes con los empiristas necesitaba de hechos, testimonios comprobables, sobre los que poder ejecutar sus métodos para falsar o validar el conocimiento. El problema para ellos era que no tenían la preparación ni el tiempo suficientes como para poder llevar a buen puerto empeño tan notable como es querer cambiar el pasado. Alguien con la cultura y el buen saber hacer de José Marchena, por ejemplo, consiguió durante bastante tiempo hacer pasar por hallazgo auténtico su falsificación de un fragmento de Petronio. Flores y Medina Conde ofrecían a su ciudad y a la cristiandad una memoria distinta de los hechos, una memoria amañada pero que acabó siendo real, gracias a los descubrimientos que se hicieron.

Sin saberlo, estos falsificadores, que proyectaban sobre el pasado una mirada imaginativa junto con unos valores y una moral contemporáneos, aplicaban a su labor el concepto fantasía, que Giambattista Vico acuñó en su Scienza nuova (1744), y que no es otra cosa que la «imaginación histórica», requisito indispensable, según el filósofo italiano, para entender las culturas del pasado ${ }^{33}$. El hecho es que, desde su visión del presente y con sus intereses contemporáneos, pretendieron una representación del pasado interesada, como lo son todas, que les llevó a los tribunales, por no ajustarse a las razones políticas del momento que validaban unos discursos sobre otros y por pervertir las normas científicas al no emplearlas honestamente.

En su caso, como en el de los políticos que auspiciaban la escritura de la Historia con criterios científicos, el conocimiento del pasado no era en realidad el fin perseguido, sino un medio para alcanzar otro objetivo, ya de tipo político, ya económico. Porque, en ocasiones, el discurso intelectual y los avances en la ciencia, la crítica, chocaban con los intereses del poder, $y$, en ese enfrentamiento, solía hacerse un uso interesado tanto de los métodos como de los resultados. Se «corregía» la historia, como indicó Medina Conde, y como hizo, entre otros, el padre Flórez, cuando no se refirió a estas falsificaciones en su momento y cuando aconsejó a Rávago, confesor de Fernando VI, que arrancara y quemara dos folios del códice De habitu clericorum, del que era autor Leovigildo de Córdoba, que se encontraba en la biblioteca del Escorial, porque, al parecer, iban "contra el honor de España» ${ }^{34}$.

33 Berlin, I., El fuste torcido de la humanidad, Barcelona, 2002, 128.

${ }^{34}$ Mestre, A., Historia, fueros y actitudes politicas. Mayans y la historiografia del siglo XVIII, Valencia, 1970, 93-95, narra con detalle este episodio. 
En esto no eran diferentes unos de otros. La Historia nunca es objetiva y la escriben algunos: los medios, los testimonios y documentos, sólo sirven para afianzar un discurso y unos intereses. Falsificadores y críticos han caminado de la mano a lo largo de la historia, hasta el punto de que los métodos que emplean éstos para discriminar lo que es verdadero de lo espúreo o apócrifo deben mucho precisamente a la labor de los falsificadores ${ }^{35}$. El trabajo de éstos responde a unos intereses determinados, concretos y contemporáneos, y además a esos intereses añaden unos valores que son los propios de su tiempo, razones por las que sus contrahechuras suelen ser descubiertas con facilidad, a pesar de mezclarlas con descubrimientos reales, que es una de las estrategias empleadas para hacer verosímiles los hallazgos. En el caso granadino se emplearon todos los recursos habituales: envejecer las piezas, confundirlas con los restos auténticos, pero su integración en un sistema jerarquizado de referencias reales falló, quizá por falta de preparación de los implicados, tal vez porque es más difícil hacer pasar por auténtico un objeto falso que un apócrifo. Aunque fallaran en su empeño, el trabajo de Flores y sus colaboradores muestra que estaban al tanto de los avances en los criterios que se empleaban para autenticar la ciencia histórica, pero, como se ha indicado ya, sus intereses no estaban del lado del pensamiento oficial y no tuvieron un padre Rávago que les defendiera.

\section{RESUMEN}

En el contexto de la reforma de los métodos de investigación histórica en época ilustrada, se estudia en este trabajo el uso de la arqueología con fines políticos y nacionalistas. Para ello nos basamos en el caso de las falsificaciones granadinas de mediados del siglo XVIII.

\section{ABSTRACT}

In this article we study the forgeries of Granada in the eighteenth century, as a case of manipulation of archaeological findings with a political purpose. The context of this case is the Enlightenment reform of historical methodology.

${ }^{35}$ Caro Baroja, J., Las falsificaciones de la Historia (En relación con la de España), Barcelona, 1991. Aunque desconoce los casos españoles, véase Grafton, A., Falsarios y críticos. Creatividad e impostura en la tradición occidental, Barcelona, 2001. 